\title{
Female Athlete Triad/Relative Energy Deficiency in Sport: A Perspective Interview With Professor Barbara Drinkwater
}

\author{
Susan Carter \\ Rocky Vista University
}

\begin{abstract}
Barbara Drinkwater has been a lifelong champion of equality for women in many areas of life well before it was widely accepted. Her "walking the walk" of women breaking barriers in traditional male roles in administration and leadership is exemplified by her election as the first woman president of the American College of Sports Medicine in 1988. Some of the controversial areas in which Barbara was vocal in the arena of women in sport, besides triad/relative energy deficiency in sport, include increased opportunity and participation, total equality, acceptance of diversity, intolerance of harassment and abuse, and fairness with transgender athletes. She co-founded the evidence-based advocacy group on the international stage known as Women Sport International. As a physiologist, Barbara has had a major influence on attention to the health of the female athlete, and she produced the original pioneering work in the field. Her impactful study, "Bone mineral density after resumption of menses in amenorrheic athletes," was published in the Journal of the American Medical Association in 1986. Since that time, the female athlete triad has set the stage for research and treatment to enhance women in physical activity at all levels.
\end{abstract}

Keywords: anorexia, amenorrhea, female triad, women scientists

Professor Barbara Drinkwater has been a lifelong champion of equality for women in many areas of life, well before it was widely accepted. Her "walking the walk" of women breaking barriers in traditional male roles in administration and leadership is exemplified by her election as the first woman president of the American College of Sports Medicine in 1988. Barbara was a forerunner in the field of female athlete triad (Triad)/relative energy deficiency in sport (RED-S). Beyond this, Barbara was also vocal in the arena of women in sport, including increased opportunity and participation, total equality, acceptance of diversity, intolerance of harassment and abuse, and fairness with transgender athletes. She co-founded the evidence-based advocacy group on the international stage known as Women Sport International (WSI).

As a physiologist, Barbara has had a major influence on attention to the health of the female athlete, and she produced the original pioneering work in the field. Specifically, two landmark studies published in very high-impact journals, the New England Journal of Medicine and the Journal of the American Medical Association, in 1984 and 1986 set the stage for the Triad as an issue in female athletes. These seminal papers clearly demonstrated the link between bone mineral density and menstrual cycle status, as well as the change of bone mineral density after resumption of menses (Drinkwater et al., 1984, 1986). Since that time, the Triad, and now RED-S, has set the stage for research and treatment to enhance women and men in physical activity at all levels.

The interview below was held with Barbara in November 2017 and clearly demonstrates that, at 90 years of age, Barbara is still full of insight and wisdom to impart to all of us regarding her journey and her impactful work on the Triad/RED-S.

Carter is Director, American College of Surgeons-Accredited Education Institute Comprehensive Simulation Center, Rocky Vista School of Medicine, Parker, CO. Address author correspondence to Susan Carter at sdcarter7@gmail.com.
What was it like finding out about/recognizing the reality of the Triad? When/what were first steps? What was the "political scene" like in sport physiology at the time-accepting of the concept?

Historically, it has been literally one step at a time. Sometimes we felt we were taking a step forward, and then we experienced a setback. Recognizing the reality of the triad was shocking. I would say I was angry, perhaps even "mad as hell," when I [would] see coaches requiring female athletes to do things that might have lifelong consequences, but they worried more about winning than the well-being of the athlete. We had kids dying. There's just no excusing that. When we put out the first scientific statement in 1986 as a precursor to the Triad, it was a real wake-up call. Just as anything, there was acceptance along with pushback. I personally feel that with the International Olympic Committee (IOC) and the Medical Commission, especially under Dr. Arne Ljungqvist, we had the support of the international community. Arne, as a true women's rights advocate, helped champion many causes, including the Triad.

We met at the Olympic Training Center in Colorado Springs in 1982 at a meeting of the Athletic Amenorrhea Bulletin, when the singer Karen Carpenter was suffering from anorexia. Her situation brought heightened public awareness of the condition. As anorexia was one of the original concerns of the Triad, along with osteoporosis and amenorrhea, do you feel there has been a significant change in the public's perception of body image over 35 years?

Body image has been a long-term battle, in some sports more than others. Fortunately, successful female athletes come in all shapes and sizes; there are muscular, fit, healthy women competing at all levels. Variably proportioned role models for girls and women have emerged all over. This has helped with body image, and recent campaigns have promoted "feeling comfortable in one's own skin." Not so in the past, when image problems were rampant as some coaches preached [a] 


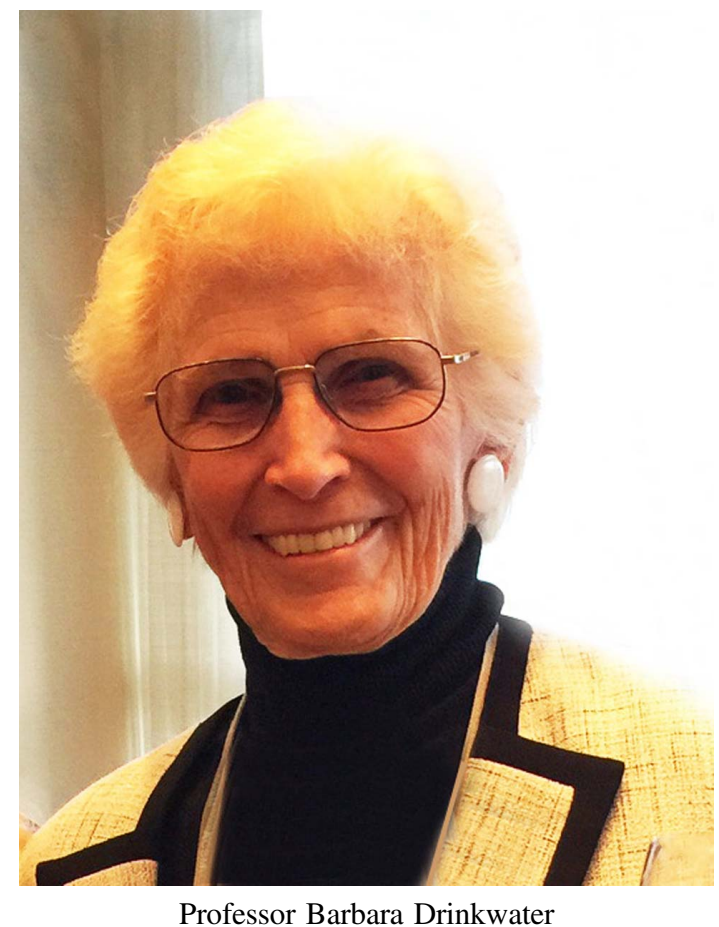

Professor Barbara Drinkwater

"the skinnier, the faster" concept. Image issues have also occurred regarding women wanting to compete in uniforms that are practical, warm, and comfortable. Federation mandates requiring women to wear a skirt, a skimpy outfit, or anything that is inappropriate on the athletic field have been seen, for example, in badminton and beach volleyball on an international level. Part of the problem has been inadequate female representation on governing bodies. Amongst other statements I have said-maybe stated stronger - that all athletes should be appreciated for their skill, not their wardrobe. Women should not be used as sex objects to boost the sport's profile among viewers.

We've been through many Updates and Position Stands over the years. What are your thoughts on the evolution of the science, such as the inclusion of men in RED-S?

I have believed for a long time that men suffer the same problem, often unrecognized. I think RED-S is the natural evolution as more information and studies have come about. We need to move on. Any athlete with energy deficiency needs to be identified and be given help, above all else. The more cohesive the sports medicine community is, the better it will be for the athletes. Collegiality will accelerate our cause - the more working towards the same goal, the better. In unison we can speed up delivering the treatment that these athletes so desperately need.

What are your comments on the long-term effect of risk assessment and return to play (including male/female athletes and recreational athletes/active population)?

Athletes should not compete when they are not healthy. The desire to win by any individual or group of authority cannot override the concern for the athlete! The long-term ill effects, both physical and emotional, can be significant in any active person. It is even more difficult to identify energy deficiency in the recreational population because there is little or no regulating entity. Recognition and identification is key, and I feel like we have made progress in this regard. However, we are still lacking access and consistency to the treatments offered.

In the mid-nineties you were pushing for mandatory education of anorexia/osteoporosis/amenorrhea to coaches through National Sport Governing Bodies. Do you think we've made progress?

In 1995, I wrote letters to appointees of the IOC/WSI joint task force who [were] appointed by Prince de Merode regarding the female athlete triad and the serious problem that we were experiencing in the USA. Funding for a campaign targeted to female athletes at risk for eating disorders was also established, and we attempted to make it available to other countries. USA Gymnastics at the time accepted a bill of rights for athletes, coaches, and parents, as well as establishing "red flags" as a means of aiding in the recognition of athletes at risk for an eating disorder and in selecting a good sports program and coach. With Arne's help, the collaboration [IOC/WSI] presented a report on the Triad at the 1996 International PreOlympic Scientific Congress in Dallas. That is also when we began a core educational program for coaches and sports governing bodies to make education mandatory for the coaches, including the Female Athlete Triad. Ninety percent of the coaches do the right thing, but there will probably always be some outliers. The American university sport system is educating collegiate athletes on health, nutrition, and emotional well-being, among others, which is a really good thing.

Any thoughts on the future of RED-S? Do you think we will eradicate the problem anytime soon? What advice do you have for current researchers?

It has been one step at a time. With the ACSM, there's no way we are going backwards. We have more champions of the cause, more awareness, more outreach. Current researchers should always be reminded they are important, ethical scientists who can provide evidence-based, quality studies that can affect the lives of many.

Anything you'd like to add?

Whenever the desire to win is stronger than anything else, we will have problems with sacrificing the well-being of the athlete, whether it's male or female. RED-S is only one of many problems that we, as the sports medicine community, should continue to research, address, treat, and cure.

For further reading, please also see these seminal papers by Barbara and colleagues (Drinkwater et al., 1984, 1986, 1990; Nattiv et al., 1994; Rencken et al., 1996; Yeager et al., 1993).

\section{References}

Drinkwater, B.L., Bruemner, B., \& Chesnut, C.H., 3rd. (1990). Menstrual history as a determinant of current bone density in young athletes. Journal of the American Medical Association, 263(4), 545-548. PubMed ID: 2294327 doi:10.1001/jama.1990.03440040084033

Drinkwater, B.L., Nilson, K., Chesnut, C.H., 3rd, Bremner, W.J., Shainholtz, S., \& Southworth, M.B. (1984). Bone mineral content of amenorrheic and eumenorrheic athletes. The New England Journal of Medicine, 311(5), 277-281. PubMed ID: 6738640 doi:10.1056/ NEJM198408023110501 
Drinkwater, B.L., Nilson, K., Ott, S., \& Chesnut, C.H., 3rd. (1986). Bone mineral density after resumption of menses in amenorrheic athletes. Journal of the American Medical Association, 256(3), 380-382. PubMed ID: 3723725 doi:10.1001/jama.1986.03380030082032

Nattiv, A., Agostini, R., Drinkwater, B., \& Yeager, K.K. (1994). The female athlete triad. The inter-relatedness of disordered eating, amenorrhea, and osteoporosis. Clinics in Sports Medicine, 13(2), 405-418. PubMed ID: 8013041
Rencken, M.L., Chesnut, C.H., 3rd, \& Drinkwater, B.L. (1996). Bone density at multiple skeletal sites in amenorrheic athletes. Journal of the American Medical Association, 276(3), 238-240. PubMed ID: 8667570 doi:10.1001/jama.1996.03540030072035

Yeager, K.K., Agostini, R., Nattiv, A., \& Drinkwater, B. (1993). The female athlete triad: Disordered eating, amenorrhea, osteoporosis. Medicine \& Science in Sports \& Exercise, 25(7), 775-777. PubMed ID: 8350697 doi:10.1249/00005768-199307000-00003 